\title{
Medication use by middle-aged and older participants of an exercise study: results from the Brain in Motion study
}

Tania Pannu', Sarah Sharkey', Grazyna Burek', Daniela Cretu', Michael D. Hill ${ }^{1,2,3}$, David B. Hogan 3,4 and Marc J. Poulin ${ }^{1,4,5,6^{*}}$

\begin{abstract}
Background: Over the past 50 years, there has been an increase in the utilization of prescribed, over-the-counter (OTC) medications, and natural health products. Although it is known that medication use is common among older persons, accurate data on the patterns of use, including the quantity and type of medications consumed in a generally healthy older population from a Canadian perspective are lacking. In this study, we study the pattern of medication use in a sedentary but otherwise healthy older persons use and determined if there was an association between medication use and aerobic fitness level.
\end{abstract}

Methods: All participants enrolled in the Brain in Motion study provided the name, formulation, dosage and frequency of any medications they were consuming at the time of their baseline assessment. Maximal aerobic capacity $\left(\mathrm{NO}_{2} \mathrm{max}\right)$ was determined on each participant.

Results: Two hundred seventy one participants (mean age $65.9 \pm 6.5$ years; range $55-92 ; 54.6 \%$ females) were enrolled. Most were taking one or more $(1+)$ prescribed medication $(n=204,75.3 \%), 1+$ natural health product $(n=221,81.5 \%)$ and/or $1+$ over-the-counter (OTC) drug $(n=174,64.2 \%)$. The most commonly used prescribed medications were HMGCoA reductase inhibitors (statins) $(n=52,19.2 \%)$. The most common natural health product was vitamin $\mathrm{D}(n=201,74$. 2\%). For OTC drugs, non-steroidal anti-inflammatories $(n=82,30.3 \%)$ were the most common. Females were more likely than males to take $1+$ OTC medications, as well as supplements. Those over 65 years of age were more likely to consume prescription drugs than their counterparts $(p \leq 0.05)$. Subjects taking more than two prescribed or OTC medications were less physically fit as determined by their $\mathrm{VO}_{2}$ max. The average daily Vitamin D intake was $1896.3 \mathrm{IU}$ per participant.

Conclusions: Medication use was common in otherwise healthy older individuals. Consumption was higher among females and those older than 65 years. Vitamin D intake was over two-fold higher than the recommended $800 \mathrm{IU} /$ day for older persons, but within the tolerable upper intake of 4,000 IU/day. The appropriateness of the high rate of medication use in this generally healthy population deserves further investigation.

Keywords: Natural Health Products, Prescription drugs, Geriatrics, Polypharmacy

\footnotetext{
*Correspondence: poulin@ucalgary.ca

'Department of Physiology and Pharmacology, Hotchkiss Brain Institute,

Cumming School of Medicine, University of Calgary, HMRB-210, 3330

Hospital Drive NW, Calgary, AB T2N 4N1, Canada

Full list of author information is available at the end of the article
} 


\section{Background}

Approximately $60 \%$ of older persons live a sedentary lifestyle and do not engage in sufficient physical activity to acquire health benefits [1]. Physical inactivity is a known modifiable risk factor for cerebrovascular disease and dementia [2, 3]. The doubling of the older population over the next 25 years will be associated with increases in the numbers of those with cognitive decline and dementia [4].

Between 1997 and 2007, Canada was second to the United States in the growth of prescription drug expenditure per capita [5]. Annual growth was $10.1 \%$, and by the end of this period, prescription drug expenditures had become the second largest component of health care spending in Canada [5]. Heavy use of pharmaceuticals becomes particularly marked at older age ranges [6-9]. Eighty three percent of community-dwelling Canadians 65-79 years of age in 2007-2011 were taking prescription medication with $33 \%$ taking 5 or more [6]. In addition to prescribed medications, there is a widespread use of over-the-counter (OTC), dietary supplements, and alternative agents even within healthy populations $[5,8,10,11]$. The use of complementary and alternative medicine (CAM), defined by Health Canada as being for the "diagnosis, treatment and/or prevention that complements mainstream medicine", is very common with a large proportion of adults using natural health products. Although the rise in the use of pharmaceuticals is well known, the pattern of the combined use of the various types of medications being consumed by individuals is less well defined. Few studies have described medication use in a unique population composed of otherwise healthy middle-aged and older sedentary Canadians.

The Brain in Motion (BIM) study is a quasiexperimental prospective cohort study designed to determine the effect of aerobic exercise for six months on cognitive function and cerebrovascular physiology in the sedentary older adults enrolled in our study. Because of the study's exclusionary criteria, the study population was anticipated to be healthier than the general population of Canadians of a similar age. The purpose of this study was to describe the pattern of medication use by study participants at baseline prior to the exercise intervention component of the BIM study. Furthermore, we examined whether there was an association between participants' fitness levels and the use of medications. Given their health status, we hypothesized these participants would show lower levels of medication consumption compared with similarly aged Canadians.

\section{Methods}

$\mathrm{BIM}$ is an 18-month quasi-experimental prospective cohort study examining the role of exercise on cognitive function and cerebrovascular physiology [12]. The study consisted of three six-month phases: 1) pre-intervention phase; 2) aerobic exercise intervention phase; and 3) post-intervention phase (Fig. 1) [12]. The Conjoint Health Research Ethics Board at the University of Calgary approved the study, and participants provided written informed consent prior to participating in the study. Medication use was obtained at the time of the baseline assessment (Pre-intervention Phase 1A) (Fig. 1), during which time participants were asked to list the name, formulation, dosages, and frequency of consumption of all medications and supplements that they were currently taking. These agents were then categorized as prescribed (i.e., require a prescription to be obtained from their physician) and non-prescribed, which were further sub-categorized as OTC medications (i.e., available for purchase without a prescription) as natural health products (which included vitamins and minerals, herbal remedies, homeopathic medicines, traditional medicines, or probiotics). We defined drug use intensity as the mean number of medications consumed per person. Years of education were also recorded at baseline, and defined as total years completed in a formal education program starting with primary (elementary) school.

\section{Recruitment and eligibility}

Subjects were recruited from the City of Calgary between 2009 and 2014 through media, poster and newspaper advertisements. Potential participants provided informed written consent prior to enrollment into the study. During an initial phone interview, interested participants were assessed for their eligibility based on predetermined inclusion and exclusion criteria, as discussed below. Potential participants who successfully completed

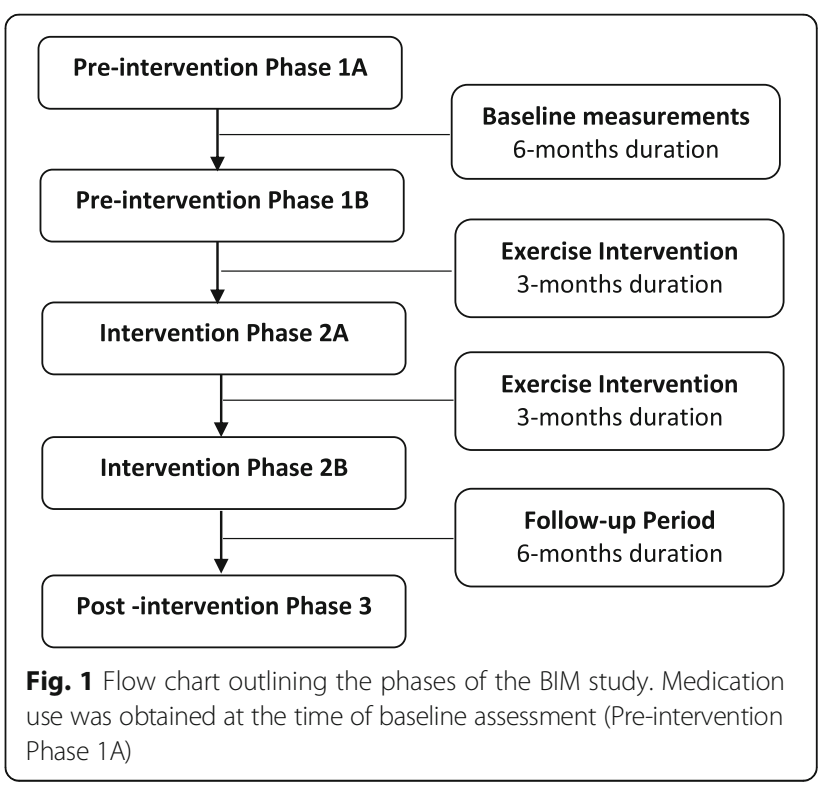


the telephone-based evaluation, were then scheduled for a 60-min on-site assessment of study eligibility [12]. Participation in the study required approval by their attending primary care physician, and physicians affiliated with the study examined all subjects at entry to ensure their safety [12].

\section{Subjects}

Subjects were sedentary men and women aged 55 years and older. Sedentary behaviour was defined as, engaged in less than $30 \mathrm{~min}$ of moderate exercise 4 days per week or 20 continuous minutes of vigorous exercise twice weekly. Inclusion criteria included: Body Mass Index of less than $35 \mathrm{~kg} / \mathrm{m}^{2}$; ability to walk independently outside and up and down at least 20 stairs; non-smoker for at least 12 months; not suffering from an active cardiovascular, cerebrovascular, or pulmonary condition that would preclude their ability to safely exercise; no major surgery or trauma within the last 6 months; free from a debilitating neurological condition; and, a Montreal Cognitive Assessment score of 24 or greater [12].

\section{Maximal aerobic capacity}

At baseline, subjects underwent assessments of fitness levels by a maximal aerobic capacity $\left(\mathrm{VO}_{2} \max \right)$ test. This was used as our measure of fitness. The $\mathrm{VO}_{2}$ max test was conducted on a motorized treadmill and follows the Bruce protocol [13]. A plateau in oxygen uptake with increasing work rate $(<2 \mathrm{~mL} / \mathrm{kg} / \mathrm{min})$, a respiratory exchange ratio of at least 1.15, and age-predicted maximal heart rate (210(age X 0.65)) were used as criteria for stopping the test (as recommended by the Canadian Society for Exercise Physiology [14] and American Thoracic Society [15]. Outcome measures for the VO2max test include oxygen uptake, carbon dioxide production, and ventilation (tidal volume and breathing frequency) [12].

\section{Data analysis}

Categorical proportions were compared using Fisher's exact of Chi2 tests. Relationships between $\mathrm{VO}_{2} \max$ and

Table 1 Baseline characteristics of subjects enrolled in the Brain in Motion study

\begin{tabular}{ll}
\hline Demographics & $\begin{array}{l}\text { Number of subjects } \\
(N=271)\end{array}$ \\
\hline Average age \pm SD & $65.9 \pm 6.5$ \\
$\%$ (number) female sex & $54.6 \%(148)$ \\
Average number of years of education \pm SD & $15.9 \pm 2.7$ \\
$\begin{array}{l}\text { Total \% (number) of participants consuming } \\
\text { + prescribed medication at baseline }\end{array}$ & $75.3 \%(204)$ \\
$\begin{array}{l}\text { Total \% (number) of participants consuming } \\
\text { 1+ natural health product at baseline }\end{array}$ & $81.5 \%(220)$ \\
Total \% (number) of participants consuming & $64.2 \%(174)$ \\
$1+$ over-the-counter medication at baseline & \\
\hline
\end{tabular}

medication usage were analyzed using a generalized linear model, whereby we determined the combined effects of sex and medication usage on $\mathrm{VO}_{2} \max$ when controlling for age.

\section{Results}

Among the 271 subjects (mean [SD] age $65.9 \pm 6.5$ years, $54.6 \%$ females) enrolled in the Brain In Motion study who completed their baseline assessment (Table 1), most

Table 2 Baseline prescribed medication use among participants ( $N=271)$ enrolled in the Brain in Motion study (listed alphabetically)

\begin{tabular}{ll}
\hline Prescribed medications & $\begin{array}{l}\% \text { total participants } \\
\text { (number) }\end{array}$ \\
\hline Drugs used for diabetes & $4.4 \%(12)$ \\
Anticonvulsant & $3.0 \%(8)$
\end{tabular}

Antihypertensive/ cardiovascular agents

${ }^{\mathrm{b}} \mathrm{ACE}$ Inhibitor $\quad$ 8.9\% (24)

Angiotensin Receptor blocker $\quad 12.5$ (34)

Beta blocker $\quad 3.7 \%(10)$

Calcium Channel blocker $\quad 10.0 \%(27)$

Diuretic 14.0\% (38)

Analgesic

b,anSAID $\quad 12.2 \%(33)$

Opioid Analgesic 3.3\% (9)

Antidepressant $\quad 14.4 \%$ (39)

Benign Prostrate Hyperplasia Agent

Alpha blocker 2.6\% (7)

Cholesterol lowering agent

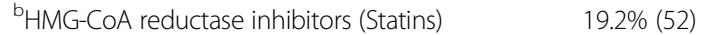

Hormonal agent

Estrogen $\quad 9.2 \%(25)$

Corticosteroid $\quad 7.4 \%(20)$

Progesterone 2.6\% (7)

Thyroxine $\quad 17.0 \%$ (46)

Proton Pump Inhibitor $\quad 7.4 \%$ (20)

Sleep aids

Melatonin Receptor Agonist $\quad 3.3 \%$ (9)

Sedatives $\quad 12.2 \%(33)$

Other

$\begin{array}{ll}\text { Antispasmodic } & 3.3 \%(9) \\ \text { Bisphosphonate } & 7.0 \%(19) \\ \text { Prostaglandin } & 5.9 \%(16) \\ \text { Other } & 24.7 \%(67) \\ \text { None } & 24.7 \%(67)\end{array}$

${ }^{\mathrm{b}} A C E$ Angiotensin Converting Enzyme

NSAID Non-Steroidal Anti-Inflammatory Drug

HMG-CoA 3-Hydroxy-3-Methyl-Glutaryl-CoA

aThese include only prescribed NSAIDs 
subjects were taking at least one prescription drug (75.3\%), natural health product (81.5\%), and/or OTC drug (64.2\%). The most commonly prescribed medications were cholesterol lowering agents (specifically HMG-CoA reductase inhibitors or statins) and thyroid replacement therapy (Table 2). Vitamin D was the most common natural health product consumed, while nonsteroidal anti-inflammatories (NSAIDs) were the most common OTC medication reported (Table 3). The average daily vitamin D intake was 1896 IU per participant with $42 \%$ of participants taking more than 2000 IU per day and $10 \%$ above 4000 IU (Table 4 ).

More females than males were taking one or more OTC medications (70\% women v 57\% men). Natural health products ( $58 \%$ women $\mathrm{v} 42 \%$ men) and prescribed medications ( $78 \%$ women $\mathrm{v} 72 \%$ men) use was similar between the sexes. Older subjects (age $>65$ years) were more likely to be taking at least one medication in all three categories and had a higher prescribed drug use intensity (mean number of medications consumed per person) (Table 5). When controlling for age, men and women taking more than two prescribed or OTC
Table 4 Vitamin D analysis in 201 participants on Vitamin D supplements. This analysis does not include dietary intake

\begin{tabular}{ll}
\hline Vitamin $D$ analysis, $N=201$ (per day) & \\
\hline Recommended intake $(I U)^{*}$ & 1800 \\
Average intake $(I U)$ & 1400 \\
Median intake $(I U)$ & 200 \\
Minimum dosage (IU) & 12000 \\
Maximum dosage $(I U)$ & $79.1(159)$ \\
$\%$ of subjects taking $>800 ~ I U(n)$ & $41.8(84)$ \\
$\%$ of subjects taking $\geq 2000 \mathrm{IU}(\mathrm{n})$ & $9.5(19)$ \\
\hline
\end{tabular}

*IU International Units

medications were less physically fit, as determined by their $\mathrm{VO}_{2}$ max measurements (Table 6).

\section{Discussion}

This study presents data on the pattern of medication use in sedentary but otherwise generally healthy middleaged and older adults. According to the Chief Public Health Officer's Report on the State of Public Health in

Table 3 Baseline supplement, natural produce and over-the-counter medication use among participants $(N=271)$ enrolled in the brain in motion study

\begin{tabular}{|c|c|c|c|}
\hline Natural health products & \% Total participants (number) & Over-the-counter medication & \% Total participants (number) \\
\hline Antioxidants & $4.8 \%(13)$ & Analgesic & $29.9 \%(81)$ \\
\hline Coenzyme Q10 & $7.0 \%(19)$ & Antihistamine & $4.8 \%(13)$ \\
\hline Digestive Enzymes & $2.2 \%(6)$ & Laxative & $3.3 \%(9)$ \\
\hline Ginkgo & $2.6 \%(7)$ & Muscle Relaxant & $2.2 \%(6)$ \\
\hline Ginseng & $2.2 \%(6)$ & NSAID & $30.3 \%(82)$ \\
\hline Glucosamine & $18.8 \%(51)$ & Sedative & $1.8 \%(5)$ \\
\hline Lutein & $7.5 \%(20)$ & Other & $10.0 \%(27)$ \\
\hline Melatonin & $1.8 \%(5)$ & None & $35.8 \%(97)$ \\
\hline \multicolumn{4}{|l|}{ Minerals } \\
\hline Calcium & $27.7 \%(75)$ & & \\
\hline Other (e.g. magnesium, zinc) & $16.6 \%(45)$ & & \\
\hline Multi-vitamins & $33.9 \%(92)$ & & \\
\hline Omega 3 & $37.6 \%(102)$ & & \\
\hline Plant Oil & $4.1 \%(11)$ & & \\
\hline Probiotics & $4.4 \%(12)$ & & \\
\hline \multicolumn{4}{|l|}{ Vitamins } \\
\hline Vitamin $D^{*}$ & $74.2 \%(201)$ & & \\
\hline Vitamin C & $15.9 \%(43)$ & & \\
\hline Vitamin $\mathrm{E}$ & $7.7 \%(21)$ & & \\
\hline B-complex & $18.1 \%(49)$ & & \\
\hline Other (e.g. A, K) & $1.8 \%(5)$ & & \\
\hline Other & $32.5 \%(88)$ & & \\
\hline None & $45.8 \%(124)$ & & \\
\hline
\end{tabular}

*Includes 180 unique participants taking a vitamin $\mathrm{D}$ supplement and 21 taking multivitamins not on a separate vitamin $\mathrm{D}$ supplement 
Table 5 Number (\%) of people taking prescribed medications according to the age group and number of medications per person $(N=271)$

\begin{tabular}{llll}
\hline $\begin{array}{l}\text { Number of } \\
\text { prescribed } \\
\text { medications }\end{array}$ & $\begin{array}{l}\text { Age group } \\
\text { \%65 (number) }\end{array}$ & $\begin{array}{l}>65(N=144) \\
\% \text { (number) }\end{array}$ & $P$-value* \\
\hline 0 & $30.7(39)$ & $19.4(28)$ & 0.019 \\
1 & $22.8(29)$ & $22.2(32)$ & \\
2 & $20.5(26)$ & $20.8(30)$ & \\
3 & $14.2(18)$ & $13.2(19)$ & \\
4 & $7.9(10)$ & $8.3(12)$ & \\
5 or more & $3.9(5)$ & $16.0(23)$ & \\
\hline
\end{tabular}

*Fisher's exact test

Canada 2010, approximately one-quarter (23\%) of Canadian older persons (i.e., 65 or more years of age) suffered from cardiovascular disease and over $4 \%$ from stroke. Those with active cardiovascular or debilitating neurological conditions were excluded from entry into our study, which also recruited a number of individuals less than 65 years of age [16]. While $62 \%$ of Canadian seniors reported being in very good functional health, nearly one-quarter of them had difficulties with activities such as walking, communicating, seeing, and climbing stairs [16]. BIM participants had to be able to function independently without difficulties. They were able to perform moderate physical activity three times a week, for the 6-month intervention period, and also underwent demanding physiological testing (such as $\mathrm{VO}_{2}$ max tests) a number of times during the 18-month study.

Most subjects $(75.3 \%)$ were taking at least one prescription drug at baseline (most commonly used were cholesterol lowering agents and L-thyroxine) (Table 2). Canadians in general are heavy users of prescribed medications. A total of $\$ 27,734$ million (or $\$ 795.32$ per capita) was spent on prescription drugs nationally in 2012 [6, 17]. In 2012 the most common prescription medication used by older persons in Canada were statins (46.6\%), followed by angiotensin-converting-enzyme (ACE) inhibitors (28.4\%) and proton pump inhibitors (27\%) [18]. While BIM participants commonly were taking statins, their rate of use (19.2\%) was less than half of that reported for the general older population (Table 2). Use of ACE inhibitors (8.9\%) and proton pump inhibitors $(7.4 \%)$ was also substantially lower than that reported for the general older Canadian population [9]. This is consistent with our impression that study participants were generally healthier than the older Canadian population. Similar to other studies female sex and older age were associated with a greater intensity of prescribed medication use [6-9].

A majority of subjects were taking at least one natural health product $(81.5 \%)$ or OTC medication $(64.2 \%)$ (Table 1). NSAIDs were the most commonly used OTC medication (30.3\%) in our study. One of the commonest reason for supplement use is a desire to improve or maintain overall health [19]. There are limited data to support the health benefits of supplements and natural products in generally healthy individuals, and there is a potential, albeit small, of risk of harm with their use. Adverse drug effects and drug-drug interactions can occur [20-33]. Supplements can reduce the efficacy of specific medications [10, 22-25, 28-37] while the consumption of multiple agents concurrently is associated with a higher risk of non-adherence [35]. Although prescription medications have a higher likelihood of side effects, there is greater regulatory oversight. Since these medications require a prescription, physicians and pharmacists should be informing patients of potential side effects and monitoring for them. With OTC medications the attending physician may be unaware of their use (which is commonly the case) [29] with no monitoring for side effects and assessment for potential interactions. Consumption of these agents tends to increase with age [36]. The use of medications (prescription and OTC) is associated with a decrease in the fitness levels of participants (Table 6). Because of the observational nature of this study no conclusions about a causal relationship can be made. Possibly the presence of various clinical conditions alone or in combination with other ones are associated with both medication use and worse fitness levels.

Nearly three-quarters of our study population were taking vitamin D. The average daily intake was 1896 IU

Table 6 Physical fitness analysis using VO2 max levels in 261 participants consuming OTC and prescription medication

\begin{tabular}{|c|c|c|c|c|c|c|c|c|c|}
\hline \multirow{2}{*}{$\begin{array}{l}\text { Medication } \\
\text { Count }\end{array}$} & \multicolumn{3}{|c|}{ All Participants } & \multicolumn{3}{|c|}{ Female } & \multicolumn{3}{|c|}{ Male } \\
\hline & $N$ & VO2 max Mean(SD) & $P$-value & $N$ & VO2 $2_{\text {max }}$ Mean(SD) & $P$-value & $N$ & VO2 max Mean(SD) & $P$-value \\
\hline 0 & 57 & $28.36(6.02)^{*}$ & - & 24 & $24.59(5.17)$ & - & 33 & $31.10(5.08)$ & - \\
\hline 1 & 65 & $27.23(5.63)^{*}$ & $>0.05^{\mathrm{a}}$ & 35 & 24.6(4.94) & $>0.05^{\mathrm{a}}$ & 30 & $30.30(4.82)$ & $>0.05^{\mathrm{a}}$ \\
\hline 2 & 53 & $25.28(4.69)$ & $0.03^{b}$ & 29 & $23.55(4.04)$ & $0.04^{b}$ & 24 & $27.36(4.63)$ & $0.04^{b}$ \\
\hline$>3$ & 86 & $23.72(4.36)^{*}$ & $<0.001^{c}$ & 53 & $22.26(3.67)$ & $0.005^{c}$ & 33 & $26.06(4.40)$ & $<0.001^{c}$ \\
\hline
\end{tabular}


per participant with nearly half consuming more than 2000 IU per day and 10\% above 4000 IU (Table 4). Nearly half (47.5\%) of the Canadian population is reportedly taking supplemental vitamin $\mathrm{D}$ [38] at a median dose of $400 \mathrm{IU} /$ day [39]. Factors reported to be associated with a greater likelihood of use included increasing age, female sex, English language, diagnosis of osteoporosis, perceived lactose intolerance, and university education [38]. In postmenopausal women and men above 50, vitamin $\mathrm{D}$ and calcium supplementation might lead to increased bone density and reduce the risk of falls and hip and non-vertebral fractures [40] though these claims are controversial $[41,42]$. Adults over 50 years of age are at a moderate risk of vitamin D deficiency. Vitamin dosages as high as $2000 \mathrm{IU} /$ day can safely be given without the need for any monitoring [39, 43]. While some feel doses up to $4000 \mathrm{IU} /$ day are safe [44], others believe that doses above $2000 \mathrm{IU} /$ day should be supervised because of potential risks of hypercalcemia and renal dysfunction [40, 43].

Our study had a number of limitations. We did not know the indications for the medications taken, or whether they were effective for the indication of their use. We were unable to determine whether OTC medications were recommended by a physician or taken without their advice or knowledge. We did not assess adherence. Together, this means that we cannot comment on the appropriateness of the medications being taken. Our emphasis was on describing overall use rather than understanding their indications. Finally, given the strict inclusion criteria for the Brain in Motion study, our findings relating to the medication use in this group, may not be representative of the general population.

\section{Conclusion}

This study showed high medication use (prescribed, OTC, and natural health products) in a generally healthy group of middle-aged and older Canadians. Consumption was higher in females, and amongst those older than 65 years. Higher medication usage was associated with a lower fitness level. Rate of medication use was lower than that of the general older Canadian population. The appropriateness of this the high rate of medication use in this generally healthy population deserves further investigation.

\section{Abbreviations \\ BIM: Brain in motion; CAM: Complementary and alternative medicine; NSAID: Non-steroidal anti inflammatory; OTC: Over the counter}

\section{Acknowledgements}

The authors thank all collaborators, staff, trainees and participants of the Brain in Motion project.

\section{Funding}

TP was supported by an Alberta Innovates - Health Solution summer studentship award. SS was supported by the Brenda Strafford Foundation Chair in Alzheimer Research (BSFCAR) and by a Natural Sciences and
Engineering Research Council (NSERC) summer studentship. DBH holds the Brenda Strafford Foundation Chair in Geriatric Medicine. MJP holds the BSFCAR. The funding for the study was provided by $\mathrm{CIHR}$ (PI = MJP, CoApplicants $=\mathrm{MDH}$ and DBH) and the BSFCAR. The funders played no role in the concept and design of this study, analysis or interpretation of the data, or drafting and critical revision of the manuscript.

\section{Availability of data and materials}

The minimal dataset underlying the findings in the manuscript are available from the corresponding author on reasonable request.

\section{Authors' contributions}

$\mathrm{MDH}, \mathrm{DBH}$, and MJP conceived the experimental design. MDH, DBH and MJP led, guided and oversaw the analytical (data collection, validation, final analyses) work, which was conducted by TP, SS, GB, and DC. TP, MDH, DBH, and MJP contributed to the interpretation of the data and revision of the manuscript. Primary supervision for TP was provided by MDH, and supervision for SS, GB, and DC was provided by MJP. All co-authors contributed to the interpretation of the data and revision of the manuscript. All authors have read and approved the final version of the manuscript.

\section{Authors' information}

TP is a medical resident at the University of Calgary, Calgary Alberta. SS is an undergraduate student at the University of Saskatchewan. GB is a third year medical student at the University of Calgary. DC is the Brain in Motion study coordinator. MDH is a stroke neurologist in Calgary. He is also the Director of the Stroke Unit for Calgary Stroke Program and professor in the Department of Clinical Neurosciences. DBH is a specialist in Geriatric Medicine who has served as the President of the Canadian Geriatrics Society and editor of Canadian Journal of Geriatrics. He also holds the Brenda Strafford Foundation Chair in Geriatric Medicine at the University of Calgary. MJP is a Professor in the Department of Physiology \& Pharmacology (Cumming School of Medicine) and holds the Brenda Strafford Foundation Chair in Alzheimer Research. He is PI of the Brain in Motion study.

\section{Competing interests}

The authors declare that they have no competing interests.

\section{Consent for publication}

Not applicable.

\section{Ethics approval and consent to participate}

The Conjoint Health Research Ethics Board at the University of Calgary approved the study, and participants provided written informed consent prior to participating in the study (Reference number REB14-2284).

\section{Author details}

'Department of Physiology and Pharmacology, Hotchkiss Brain Institute, Cumming School of Medicine, University of Calgary, HMRB-210, 3330 Hospital Drive NW, Calgary, AB T2N 4N1, Canada. ${ }^{2}$ Calgary Stroke Program, Department of Clinical Neurosciences, University of Calgary, Foothills Hospital, Rm 1242A, 1403 29th Street NW, Calgary, AB T2N 2 T9, Canada.

${ }^{3}$ Department of Medicine, Cumming School of Medicine, University of Calgary, Calgary, Canada. ${ }^{4}$ Department of Clinical Neurosciences, Cumming School of Medicine, University of Calgary, Calgary, Canada. ${ }^{5}$ Faculty of Kinesiology, University of Calgary, Calgary, Canada. 'Libin Cardiovascular Institute of Alberta, University of Calgary, Calgary, Canada.

Received: 1 October 2015 Accepted: 20 January 2017

Published online: 10 February 2017

\section{References}

1. Canada's Physical Activity Guide to Healthy Active Living for Older Adults. http://csep.ca/CMFiles/Guidelines/CSEP_PAGuidelines_older-adults_en.pdf. Accessed June 2014.

2. Gorelick PB, Sacco RL, Smith DB, Alberts M, Mustone-Alexander L, Rader D, Ross JL, Raps E, Ozer MN, Brass LM, Malone ME, Goldberg S, Booss J, Hanley DF, Toole JF, Greengold NL, Rhew DC. Prevention of a first stroke: a review of guidelines and a multidisciplinary consensus statement from the national stroke association. J Am Med Assoc. 1999;281(12):1112-20. 
3. Laurin D, Verreault R, Lindsay J, MacPherson K, Rockwood K. Physical activity and risk of cognitive impairment and dementia in elderly persons. Arch Neurol. 2001;58(3):498-504.

4. Bishop NA, Lu T, Yankner BA. Neural mechanisms of ageing and cognitive decline. Nature. 2010;464(7288):529-35.

5. Canadian Institute for Health Information. Drivers of Prescription Drug Spending in Canada. Ottawa, ON: ClHl; 2012.

6. Rotermann M, Sanmartin C, Hennessy D, Arthur M. Prescription medication use by Canadians aged 6 to 79. Statistics Canada, Catalogue no.: 82-003-X. Health Rep. 2014;25(6):3-9.

7. Morgan S, Smolina K, Mooney D, Raymond C, Bowen M, Gorczynski C, et al. The Canadian Rx Atlas. 3rd ed. Vancouver: Centre for Health Services and Policy Research, University of British Columbia; 2013.

8. Ramage-Morin PL. Medication use among senior Canadians. Health Rep. 2009;20(1):37-44.

9. Mo F, Morrison H, Liepold H, Underhill L. Drug utilization in Canadian patients with major chronic diseases. Am J Pharm Benefits. 2011;3(3):e42-50.

10. Nahin RL, Pecha M, Welmerink DB, Sink K, DeKosky ST, Fitzpatrick AL. Concomitant use of prescription drugs and dietary supplements in ambulatory elderly people. J Am Geriatr Soc. 2009;57(7):1197-205.

11. Qato DM, Alexander GC, Conti RM, Johnson M, Schumm P, Lindau ST. Use of prescription and over-the-counter medications and dietary supplements among older adults in the United States. JAMA. 2008;300(24):2867-78.

12. Tyndall AV, Davenport MH, Wilson BJ, Burek GM, Arsenault-Lapierre G, Haley $E_{\text {, et }}$ al. The brain-in-motion study: effect of a 6-month aerobic exercise intervention on cerebrovascular regulation and cognitive function in older adults. BMC Geriatr. 2013;13:21.

13. Paterson DH, Cunningham DA, Koval JJ, St. Croix CM. Aerobic fitness in a population of independently living men and women aged 55-86 years. Med Sci Sports Exerc. 1999;31(12):1813-20.

14. Canadian Society for Exercise Physiology. Professional Fitness and Lifestyle Consultant: Resource Manual, Canadian Society for Exercise Physiology. Ottawa: Canadian Society for Exercise Physiology; 1996.

15. Anonymous. ATS/ACCP Statement on cardiopulmonary exercise testing. Am J Respir Crit Care Med. 2003;167(2):211-77.

16. Butler-Jones D. The Chief Public Health Officer's Report on the State of Public Health in Canada, 2009: Growing older - Adding life to years. Ottawa, ON: Public Health Agency of Canada; 2009. p. 2010.

17. Canadian Institute for Health Information. Drug Expenditure in Canada, 1985 to 2012. Ottawa, ON: ClHI; 2013.

18. Canadian Institute for Health Information. Drug Use Among Seniors on Public Drug Programs in Canada, 2012: Revised October 2014

19. Bailey RL, Gahche JJ, Miller PE, Thomas PR, Dwyer JT. Why US Adults Use Dietary Supplements. JAMA Intern Med. 2013;173(5):355-61.

20. Steiner M. Effect of alpha-tocopherol administration on platelet function in man. Thromb Haemost. 1983;49(2):73-7.

21. Celestini A, Pulcinelli FM, Pignatelli P, Lenti L, Frati G, Gazzaniga PP, et al. Vitamin $\mathrm{E}$ potentiates the antiplatelet activity of aspirin in collagenstimulated platelets. Haematologica. 2002;87(4):420-6.

22. Gonzalez-Correa JA, Arrebola MM, Guerrero A, Muñoz-Marín J, Ruiz-Villafranca D, Sánchez de La Cuesta F, et al. Influence of vitamin E on the antiplatelet effect of acetylsalicylic acid in human blood. Platelets. 2005;16(3-4):171-9.

23. Crowe M, Wollner $L$, Griffiths RA. Hypercalcaemia following vitamin D and thiazide therapy in the elderly. Practitioner. 1984;228(1389):312-3.

24. Drinka PJ, Nolten WE. Hazards of treating osteoporosis and hypertension concurrently with calcium, vitamin D, and distal diuretics. J Am Geriatr Soc. 1984:32(5):405-7.

25. Parfitt AM. Thiazide-induced hypercalcemia in vitamin D-treated hypoparathyroidism. Ann Intern Med. 1972;77(4):557-63.

26. Sparreboom A, Cox MC, Acharya MR, Figg WD. Herbal remedies in the United States: potential adverse interactions with anticancer agents. J Clin Oncol. 2004;22:2489-503.

27. Brazier NC, Levine MA. Drug-herb interaction among commonly used conventional medicines: a compendium for health care professionals. Am J Ther. 2003:10:163-9.

28. Izzo AA, Ernst E. Interactions between herbal medicines and prescribed drugs: an updated systematic review. Drugs. 2009;69:1777-98.

29. Mehta DH, Gardiner PM, Phillips RS, McCarthy EP. Herbal and dietary supplement disclosure to health care providers by individuals with chronic conditions. J Altern Complement Med. 2008;14:1263-9.
30. Shord SS, Shah K, Lukose A. Drug-botanical interactions: a review of the laboratory, animal, and human data for 8 common botanicals. Integr Cancer Ther. 2009;8(3):208-27.

31. Gurley BJ, Swain A, Hubbard MA, et al. Clinical assessment of CYP2D6mediated herb-drug interactions in humans: effects of milk thistle, black cohosh, goldenseal, kava kava, St. John's wort, and Echinacea. Mol Nutr Food Res. 2008;52:755-63.

32. Chen XW, Serag ES, Sneed KB, Liang J, Chew H, Pan SY, et al. Clinical Herbal Interactions with Conventional Drugs: From Molecules to Maladies. Curr Med Chem. 2011;18:4836-50.

33. Hu Z, Yang X, Ho PCL, Chan SY, Heng PWS, Chan E, et al. Herb-Drug Interactions: A literature Review. Drugs. 2005;65(9):1239-82.

34. Atkin PA, Veitch PC, Veitch EM, Ogle SJ. The epidemiology of serious adverse drug reactions among the elderly. Drugs Aging. 1999;14(2):141-52.

35. McLean AJ, Le Couteur DG. Aging biology and geriatric clinical pharmacology. Pharmacol Rev. 2004;56(2):163-84.

36. Heft MW, Mariotti AJ. Geriatric pharmacology. Dent Clin North Am. 2002; 46(4):869-85. xii.

37. Vik SA, Maxwell CJ, Hogan DB. Measurement, correlates, and health outcomes of medication adherence among seniors. Ann Pharmacother. 2004;38(2):303-12

38. Janz T, Pearson C. Vitamin D blood levels of Canadians, health at a glance. Statistics Canada, Catalogue no:: 82-624-X. 2013. http://www.statcan.gc.ca/ pub/82-624-x/2013001/article/11727-eng.pdf. Accessed 19 Sept 2015.

39. Barr SI, Green TJ. Vitamin D supplement use by adult Canadians: sociodemographic correlates. FASEB J. 2013;27:1059.4.

40. Hanley DA, Cranney A, Jones G, Whiting SJ, Leslie WD, Cole DE, et al. Vitamin $D$ in adult health and disease: a review and guideline statement from Osteoporosis Canada. CMAJ. 2010;182(12):e610-8.

41. Bolland MJ, Grey A, Gamble GD, Reid IR. Vitamin D supplementation and falls: a trial sequential meta-analysis. Lancet Diabetes Endocrinol. 2014;2(7):573-80.

42. Reid IR, Bolland MJ, Grey A. Effects of vitamin D supplements on bone mineral density: a systematic review and meta-analysis. Lancet. 2014:383(9912): 146-55.

43. Holick MF, Binkley NC, Bischoff-Ferrari HA, Gordon CM, Hanley DA, Heaney $\mathrm{RP}$, et al. Evaluation, Treatment, and Prevention of Vitamin D Deficiency: An Endocrine Society Clinical Practice Guideline. J Clin Endocrinol Metab. 2011; 96(7):1911-30.

44. Judge J, Birge S, Gloth F, Heaney R, Hollis B, Kenny A, et al. Recommendations abstracted from the American geriatrics society consensus statement on vitamin D for prevention of falls and their consequences. J Am Geriatr Soc. 2014:62(1):147-52

\section{Submit your next manuscript to BioMed Central and we will help you at every step:}

- We accept pre-submission inquiries

- Our selector tool helps you to find the most relevant journal

- We provide round the clock customer support

- Convenient online submission

- Thorough peer review

- Inclusion in PubMed and all major indexing services

- Maximum visibility for your research

Submit your manuscript at www.biomedcentral.com/submit 